\title{
How Local Cultures Contribute to Local Communities? Case Studies of Japanese Spirits Dance 'Kagura'
}

\author{
Shiro Horiuchi and Mari Morino
}

\begin{abstract}
We did social survey in the Eastern Kyushu area of Japan on how local groups of 'kagura', Japanese spirits dance, have inherited their kagura festivals. The numbers of kagura dancers and guests to the festivals have increased in many groups. The ways of enlargement were different, depending on whether the festivals were closed or open to outsider tourists. In the kagura groups where the festivals were open to outsider tourists, the numbers of dancers and guests have increased, if kagura groups well advertised their areas to outsiders, young residents settled into the area and the dancers did not stick to their traditional kagura. Kagura groups enlarged not only in city areas but also in mountainous areas where depopulation and ageing are serious problems. The results suggest that local cultures could contribute to enhancement of local communities where amount of local cultures have remained whereas depopulation and ageing are serious problems.
\end{abstract}

Index Terms - Community, tourists, tradition, arts.

\section{INTRODUCTION}

In Japan, local cultures, exemplified by traditional clothes, dialects, buildings, folklores, music, dances, festivals, or else, have been the symbols through which local residents assure their community. Belonging to their communities, the residents can assure their safety and trustworthiness of the members. Local cultures, however, are on the risk of disappearing in many areas, due to the effects of globalization and individualization. Few residents now have interests or motivations to carry their cultures, since they are freed from local communities. Particularly in mountainous areas, many local residents have inherited their cultures, whereas the communities are shrinking due to depopulation and ageing. Therefore amounts of local cultures face risks of fading out in Japan. Once residents lose their local cultures, it is difficult to recover the cultures. Various organizations have tried to keep local cultures not only for the interests of museum or anthropology, but also to secure local communities and keep health of the residents [1].

Kagura is a traditional spirits dance of Japan. In kagura, individuals dance with masks of spirits. They celebrate their health, harvests, well-beings, and so on. In all prefectures of Japan, except for Hokkaido, amounts of original kagura groups have continued. Reference [2] says the tradition of

Manuscript received September 5, 2013; revised November 10, 2013. This work was supported by the MEXT KAKENHI, No. 21710051, 23101505 and 25101707.

Shiro Horiuchi is with the Shibaura Institute of Technology, Saitama, Japan (e-mail: horiuchi.shiro@gmail.com).

Mari Morino is with the Kibi International University, Minamiawaji, Japan (e-mail: morino@kibi.ac.jp). kagura may date back to the Nara era (AD. 710-794). Some believe the tradition of kagura even dates back to the era of the birth-myth of Japan, which tells how the ancestral spirits created Japan archipelagoes. The myth tells that the art spirit Uzume created kagura dance for the first time as the method to please the sun spirit Amaterasu.

Eastern Kyushu is the richest area of kagura cultures [3]. In the area, the town of Takachiho is most famous for its kagura. Residents of each village in Takachiho operate the kagura festivals once a year. The festival starts from the evening and ends in the next morning. The season of festivals is from November to February. In the festival 33 dances are sequentially performed. The festivals are the largest event in each village. The populations of villages are around 100, whereas up to 1,000 guests, composed of many outsider tourists, visit the village to attend the festival. The Ministry of Education, Culture, Sports, Science and Technology selected Takachiho kagura as the important intangible cultural asset in 1978. Recently many tourists visit Takachiho to attend the kagura festivals. Now kagura is included into the package of tourism in Takachiho area.

Not only in Takachiho, but also in surrounding municipalities, many kagura groups have performed their festivals. Some kagura are also selected as the important intangible cultural asset. Some kagura also attract many tourists. But not all the festivals are open to outsider tourists. Some festivals are held almost exclusively by local residents, as the sincere way to celebrate their spirits or community. Hence there are two types of kagura festivals, whether they are open or closed to outsider tourists.

In the previous study S.H. did participatory observation on kagura groups of Takachiho and clarified how kagura festivals worked as the bond between residents and outsider tourists [4]. The author also did social survey of kagura groups in areas of Miyazaki prefecture and clarified how kagura groups developed their cultures based on the relation between residents and tourists [5]. In the both studies, the key factor was how local residents did or did not communicate with outsider tourists. Some persons worked as mediators between residents and tourists; there appeared a bridging social capital [6], which is based on weak ties between the two parts [7]. Thanks to mediators, there appear communities that are open to outsiders.

In this study, we used the data of Miyazaki prefecture [5] and new data of Oita and Kumamoto prefectures. We test how kagura contributed to local communities, with the aid of outsider tourists on kagura festivals. Fig. 1 show the position of Takachiho and the other municipalities to which we did social survey in the three prefectures, Miyazaki, Oita and Kumamoto. With the data of kagura groups of the areas, we 
clarified how kagura festivals contributed to local communities.

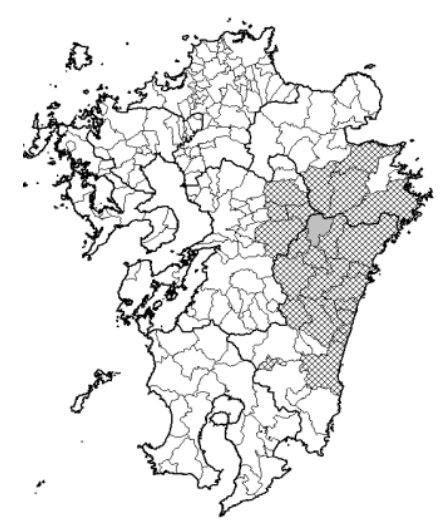

Fig. 1. Takachiho (gray) and the other municipalities (dashed) surveyed by this study. The map was created by Hakuchizu Ken-Map ver. 9.1.

\section{METHODS}

We did social survey on how local residents have transmitted their kagura groups. The procedures of surveys were as follows.

\section{A. Preliminary Survey}

The first author visited more than 50 kagura festivals of Miyazaki prefecture in 2009 - 2012 as one guest. He did participatory observation in the festivals, interviewed with dancers, residents, and outsider tourists. He also visited Kumamoto and Oita prefectures and surveyed on how kagura festivals were executed. He interviewed with officials at each municipality of the three prefectures and gained basic information for the composition and situation of each kagura group, and gained addresses of the leaders.

\section{B. Questionnaire Survey}

After gained permission from officials of each municipality, the author did questionnaire survey on 17 municipalities of Miyazaki prefecture in February of 2012 and on 10 municipalities of Oita and Kumamoto prefecture in October 2012 to leaders of 215 kagura groups. The authors gained data from in total 131 kagura groups (57\%). We deleted 4 groups since the data had missing values for the statistics. Hereafter we used the data of 127 groups.

\section{Data Analysis}

The authors used several statistics. For statistics and graphs we used $R$ ( $R$ is a language and environment for statistical computing and graphics. See http://cran.r-project.org/.). To prepare and analyze distribution of kagura groups on GIS, we used MANDARA (MANDARA is a GIS analysis soft. See http://ktgis.net/mandara/).

\section{RESULTS}

\section{A. Classification of Kagura Groups}

In order to check how kagura groups have kept their activities, we asked whether the number of dancers and guests to the festivals have changed in these 10 years. In the questionnaire four answers were prepared, increased / a bit increased / a bit decreased / decreased. Respondents selected one of the four.

Fig. 2 illustrates a strong correlation between the change of dancers and guests in number. That means, in the group where the number of dances has increased, the number of guests has also likely increased and vice versa (Chi-square test, $\chi^{2}$ value $=41.7$, d.f. $\left.=9, P<0.01\right)$.

In this study, we pay attention on in which conditions kagura groups have enlarged in number of dancers and guests. Therefore, for convenience, we categorized the 127 groups into the two; inactive groups $(n=43)$ where the number of both dancers and guests have decreased, and active groups ( $n$ $=84$ ) where the number of either dancers or guests has increased.

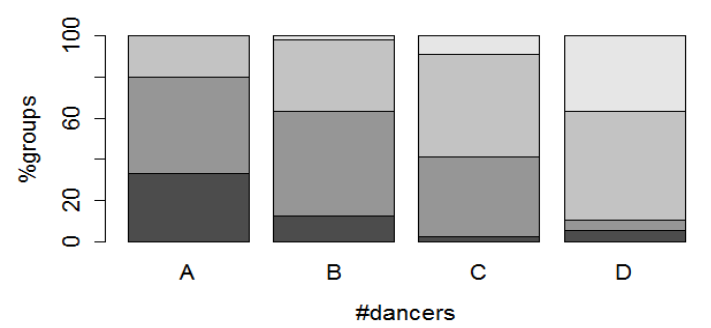

Fig. 2. Ratio of kagura groups where the number of guests has changed (Black: Increased - light gray: Decreased) along the axis with respect to the number of dancers has changed (Increased: A - Decreased: D).

To test how kagura festivals are open to outsider tourists, we asked the composition of guests. In the questionnaire four answers were prepared, mostly residents / a few outsiders / many outsiders / mostly outsiders. Respondents selected one of the four. Fig. 3 illustrates the result. Based on the figure, we categorized the kagura groups into the two: local kagura groups $(n=52)$ where the guests are mostly residents and open kagura groups $(n=75)$ where the guests include a few outsiders or more.

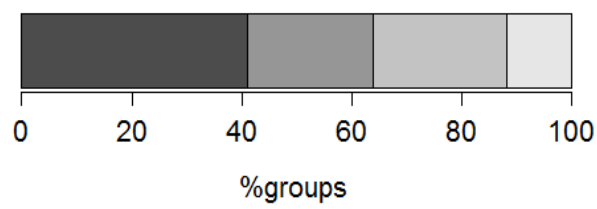

Fig. 3. Ratio of kagura groups with respect to the composition of guests (Black: Mostly residents - light gray: Mostly outsiders).

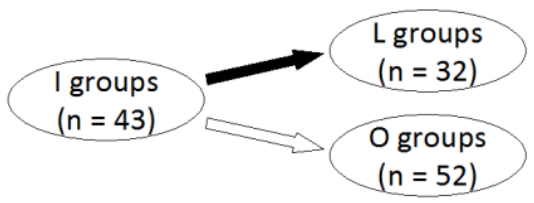

Fig. 4. The ways to activate I groups to $\mathrm{L}$ or $\mathrm{O}$ groups.

There is no significant correlation between the two parameters "active - inactive" and "local - open" $\left(\chi^{2}\right.$ value $=$ 0.83 , d.f. $=1, P>0.1)$. In other words, kagura groups can be activated by restricting the guests to the residents or open the guests to outsiders. Therefore we classified kagura groups into three: inactive groups (I. $n=43$ ), locally active groups (L. $n=32)$, and open active groups (O. $n=52)$. Fig. 4 illustrates 
the hypothesis that the way Inactive groups can be activated are different, whether they become locally active or open active. .

\section{B. Logistic Regression Analyses}

We used logistic regression analysis to test which parameters affect the difference of kagura groups, whether inactive or active. In the model 1 , the dependent parameters are inactive groups or locally active groups, whereas in the model 2 , the dependent parameters are inactive groups or open active groups. The independent parameters are the leaders' responses to the questions "which had been good to maintain your kagura". The prepared questions were as follows: 1) study of local traditions, 2) transmission of Japanese tradition, 3) young residents' settlement into the area, 4) activation of the area, 5) advertisement of the area, 6) communication among the residents, 7) communication with outsiders, 8) creation of new culture, 9) friendship among the residents, 10) matching of couples, 11) funs of dance, 12) education of young dancers. If the leader responded yes or no to the question $i(1 \leq i \leq 12)$, the value $x_{i}$ is 1 or 0 , respectively. The logistic regression analysis assumes the equation,

$$
\log \left(\frac{p}{1-p}\right)=\sum_{i=1}^{12} a_{i} x_{i}+b
$$

where $a_{i}$ represents the coefficient value of the independent parameter $x_{i}$ and $b$ represents the value of intercept. The independent parameter $p$ represents the probability that a kagura group is locally active or open active, respectively, in the model 1 or 2 .

Table I shows the estimate value of each coefficient $\left(a_{1}-\right.$ $a_{12}$ ) in the model 1 . Table I suggests that dancers of locally active kagura find kagura as fun; they on the other hand do not feel friendship among the residents through kagura, compared with the inactive kagura groups.

\section{GIS Analyses}

In order to analyze which kagura groups enlarged in numbers of dancers and guests, we used GIS analysis. Fig. 5 shows the distribution of kagura groups with the data of inactive, locally active or open active. With the data of latitude and longitude of each kagura group, we categorized them into 5 clusters, using hierarchical cluster analysis (Ward method using squared distance between kagura groups).

TABLE I: THE MODEL 1

\begin{tabular}{|c|c|c|c|}
\hline & Estimate & Std. error & \\
\hline$b$ & 0.22 & 0.68 & n.s. \\
\hline$a_{1}$ & -0.44 & 0.64 & n.s. \\
\hline$a_{2}$ & -0.60 & 0.62 & n.s. \\
\hline$a_{3}$ & 1.76 & 1.59 & n.s. \\
\hline$a_{4}$ & -0.13 & 0.57 & n.s. \\
\hline$a_{5}$ & 0.08 & 0.64 & n.s. \\
\hline$a_{6}$ & -17.0 & 1413 & n.s. \\
\hline$a_{7}$ & -0.79 & 0.57 & n.s. \\
\hline$a_{8}$ & 1.25 & 1.91 & n.s. \\
\hline$a_{9}$ & -1.90 & 0.78 & $P<0.05$ \\
\hline$a_{10}$ & NA & NA & NA \\
\hline$a_{11}$ & 1.54 & 0.59 & $P<0.01$ \\
\hline$a_{12}$ & -0.41 & 0.64 & n.s. \\
\hline
\end{tabular}

Table II shows the estimate value of each coefficient in the model 2. Table II suggests that dancers of open active kagura find kagura as fun. They also felt succeeded in advertising their areas to outsider tourists, felt satisfied for young residents' settlement into their area, and did not feel that they follow the tradition of their kagura.

TABLE II: THE MODEL 2

\begin{tabular}{cccc}
\hline \multicolumn{4}{c}{ TABLE II: THE MODEL 2} \\
\hline$b$ & -2.37 & 0.89 & $P<0.01$ \\
$a_{1}$ & -1.41 & 0.67 & $P<0.05$ \\
$a_{2}$ & -0.19 & 0.61 & n.s. \\
$a_{3}$ & 2.40 & 1.16 & $P<0.05$ \\
$a_{4}$ & 1.02 & 0.62 & $P<0.1$ \\
$a_{5}$ & 1.44 & 0.63 & $P<0.05$ \\
$a_{6}$ & -2.27 & 1.78 & n.s. \\
$a_{7}$ & 1.45 & 0.62 & $P<0.05$ \\
$a_{8}$ & 0.14 & 1.68 & n.s. \\
$a_{9}$ & -0.80 & 0.63 & n.s. \\
$a_{10}$ & 17.9 & 1600 & n.s. \\
$a_{11}$ & 2.09 & 0.62 & $P<0.001$ \\
$a_{12}$ & 0.47 & 0.63 & n.s. \\
\hline
\end{tabular}

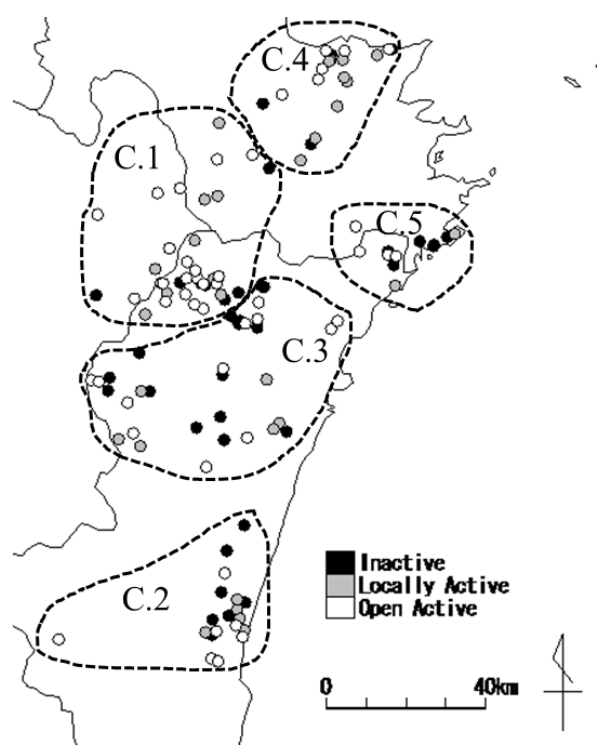

Fig. 5. Distribution of I, L and O groups in eastern Kyushu.
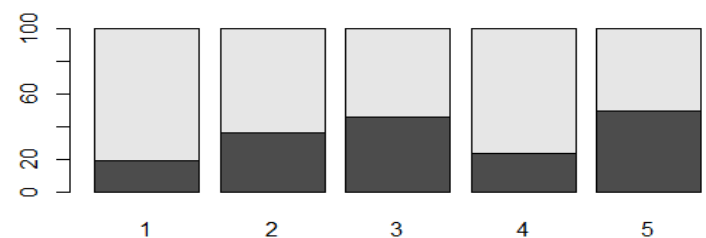

Fig. 6. The ratio of active (gray) and inactive (black) kagura groups in each cluster.

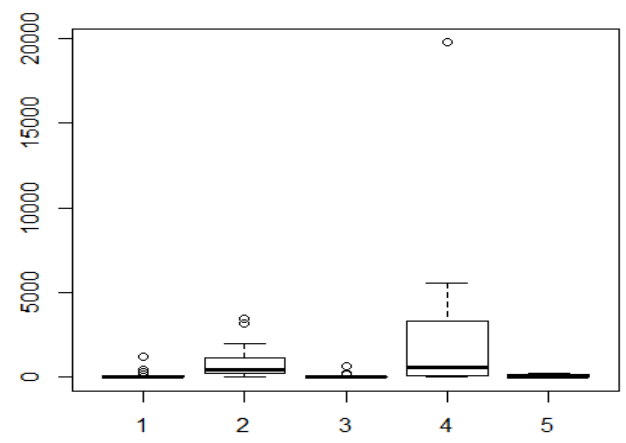

Fig. 7. Bar plot of population density for the five clusters. 


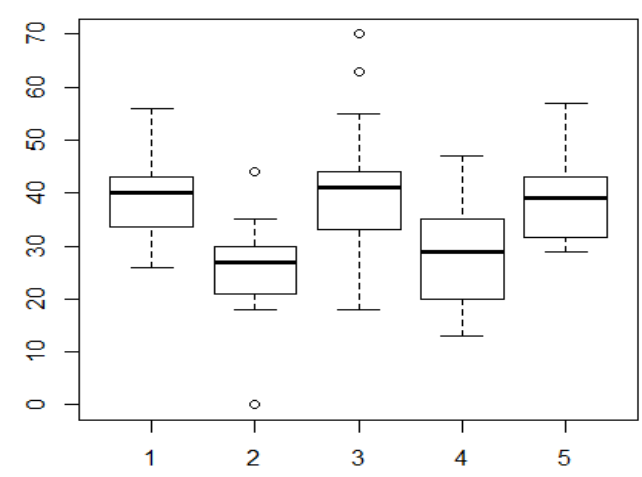

Fig. 8. Bar plot of ageing ratio for the five clusters.

We arranged kagura groups into inactive groups (I groups) or active groups ( $\mathrm{L}$ and $\mathrm{O}$ groups). The five clusters have different composition of inactive or active groups, although not statistically significantly different $\left(\chi^{2}\right.$ value $=0.83$, d.f. $=$ $4, P<0.1)$. Fig. 6 shows that the cluster 1 and 4 include relatively amounts of active kagura groups, compared with the other clusters.

We compared the five clusters with the data of population density and ageing ratio (the ratio of residents over 65 years in the population). In the both indexes, null hypotheses are rejected (ANOVA. population density, $d . f .=4, \mathrm{~F}$. value $=6.5$, $P<0.01$, Fig. 7. ageing ratio, $d . f .=4, \mathrm{~F}$. value $=11.6, P<0.01$, Fig. 8). The cluster 2 and 4, each is around Miyazaki and Oita capital city respectively, show higher population density and smaller ageing ratio.

\section{DISCUSSION}

The present study suggests that kagura groups may enlarge their festivals with respect to the numbers of dancers or guests to the festival. The ways of enlargement are different depending on the composition of guests, or the festivals are closed or open to outsider tourists. In kagura groups whose festivals are closed against outsider tourists, the festivals have enlarged if the dancers find kagura as fun. The first author did participatory observation in some kagura festivals which are usually closed to outsider tourists. The dancers appeared to be relaxed with each other. However the residents don't feel friendship among them through kagura. In other words, in inactive groups where the numbers of dancers and guests have decreased, the residents can feel friendship among them through the festival. In that sense, kagura certainly works as the symbol of declining communities.

In kagura groups whose festivals are open to outsider tourists, the festivals have enlarged if the dancers find kagura as fun, the dancers advertize their areas to outsider tourists through kagura, they don't follow the tradition of their kagura, and young residents settle into the area. Accordingly, kagura work not only as the last stand of declining communities, but also as the activator of flourishing communities. When the author did participatory observation, many dancers of Takachiho kagura told that they are glad to advertize their areas to outsider tourists. Some young dancers told they tried to find jobs in the areas to continue their kagura. They did not stick to their traditional kagura and sometimes recreated their kagura, gazed by outsider tourists.
Also they find their kagura as fun, as same as the kagura groups where the festivals are closed against outsider tourists. But the meanings of fun may be different. The dancers train themselves to show their dance to outsider tourists. They feel satisfied by showing their polished kagura to outsider tourists and find it as fun.

Whether kagura groups enlarge or not may depend on their locations. Intuitively we may predict that kagura groups can be activated whereas population density is high and relatively young residents live. In the cluster 4 , actually, many kagura groups enlarged where population density is high and ageing ratio is small. On the other hand, in the cluster 1 , although population density is lowest and ageing ratio is high, kagura groups enlarged. We have engaged in field-work study in the area. Many residents take pride in their kagura, which are rarely the cases in other areas. The key factor may lie in the development of tourism of kagura in the area.

Sociology of tourism criticizes the impact of mass tourists on local communities [8]. Actually many local communities stop their local cultures, due to the troubles with outsider tourists. Some local communities close their local culture against outsider tourist not to be disturbed. In the Eastern Kyushu, however, many kagura groups rather open their festivals to outsider tourists. They then have enlarged their festivals and activated their communities. During the festivals, residents and outsider tourists communicate with each other. The impact is not one-directional. Both are affected from each other. Hence they create enlarged communities that include residents and tourists.

\section{ACKNOWLEDGMENT}

We thank the leaders of kagura groups and officials of municipalities surveyed in this study for their cooperation. We thank the members of Tokyo Meeting for Mathematical Sociology and the members of Replacement of Neanderthals by Modern Humans for valuable comments and diiscussions.

\section{REFERENCES}

[1] H. Hoshino, Mura no dento geinou ga abunai, Tokyo: Iwata Shoin, 2009.

[2] Z. Kotegawa, Takachiho kagura, Miyazaki: Kotegawa Zenjiro Iko Shuppankai, 1976.

[3] Y. Honda, Honda Yasuji Tyoosaku-shu, Tokyo: Kinseisha, 1990, vol. 1-3.

[4] S. Horiuchi, "Community creation by residents and tourists via Takachiho kagura in Japanese rural area," Sociology Mind, vol. 2, pp. 306-312, 2012.

[5] S. Horiuchi and S. Kubota, "The effects of cross-boundary rituals on cultural innovation," RNMH, Tokyo: Springer, vol. 2.

[6] R. D. Putnam, Bowling Alone: The Collapse and Revival of American Community, New York: Simon and Schuster, 2000.

[7] M. S. Granovetter, "The strength of weak tie," American Journal of Sociology, vol. 78, pp. 1360-1380, 1973.

[8] V. L. Smith, Hosts and Guests: The Anthropology of Tourism (2nd), Philadelphia: University of Pennsylvania Press, 1989.

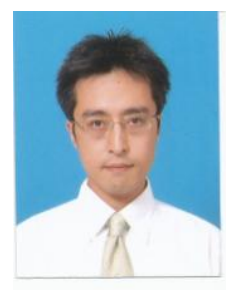

Shiro Horiuchi was born at Kyoto, Japan, on July 26, 1975. He graduated Kyoto University in 1998. He gained Ph.D. of Science at 2004, Kyoto University, Kyoto. He majors in mathematical sociology, ranged from dynamic system analysis to agent based model. He is now an associate professor of Shibaura Institute of Technology, Saitama, Japan. His selected publications are S. Horiuchi, S. Kubota, "The effects of cross-boundary rituals on cultural innovation", 
$R N M H$, vol. 2, Tokyo: Springer, in press, S. Horiuchi, "Emergence and persistence of communities: Analysis by means of a revised hawk-dove game." Sociological Theory and Methods, vol. 27, pp. 299-306, 2012, and S. Horiuchi, "Community creation by residents and tourists via Takachiho kagura in Japanese rural area." Sociology Mind, vol. 2, pp. 306-312, 2012 His main interest in research is how heterogeneous individuals cooperate or coexist. For the research question, he analyzes mathematical models and engages in field work study. He also engages in field work study of local sociology, particularly interested in communication between urban and mountainous areas of Japan. Dr. Horiuchi is the member of Japanese Association of Mathematical Sociology, The Japan Sociological Society, and Primate Society of Japan.

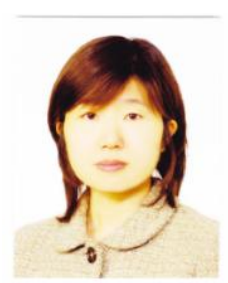

Mari Morino was born at Chiba, Japan. She graduated Okayama University in 1990. She gained Ph.D. of Engineering at 2003, Kyoto University, Kyoto. She majors in forestry management, using field work, questionnaire survey and GIS analysis. She is now associate professor of Kibi International University, Minamiawaji, Japan. Her selected publications are M. Mari, S. Horiuchi, "Effects of location on the management of small private forests.", Studies in Regional Science, vol. 40, pp. 143-155, 2010 (in Japanese)., M. Mari, A. Koike, "Assessing the risk of economic damage to crops caused by Japanese macaques on Yakushima island.", Japanese Journal of Conservation Ecology, vol. 11, pp. 43-52, 2006 (in Japanese)., and M. Morino, Y. Hagiwara, D. Kamiya, M. Sakamoto "Awareness of local people of nature conservation on Yakushima island from the perspective of non-use values of a forest.", Studies in Regional Science, vol. 34, pp. 311-324, 2004 (in Japanese). Her main interest is how individuals settle into rural areas. Dr. Morino is the member of Japanese Institution of Landscape Architects, Japan Section of the Regional Science Association, and the Japanese Forest Society. 